\title{
RECENT PROGRESS ON MICORCRYSTALLINE SOLAR CELLS
}

\author{
A. Shah, J. Meier, P. Torres, U. Kroll, D. Fischer, N. Beck, N. Wyrsch, and H. Keppner \\ Institute of Microtechnology, University of Neuchâtel, A.-L. Breguet 2, CH-2000 Neuchâtel, Switzerland
}

\begin{abstract}
The most important features of microcrystalline silicon ( $\mu \mathrm{c}-\mathrm{Si}: \mathrm{H}$ ) and microcrystalline silicon based $\mathrm{p}-\mathrm{i}-\mathrm{n}$ solar cells (specially those deposited by VHF-Glow Discharge) are reviewed. Since such material has been recognized to be a photovoltaically active material, stabilized cell efficiencies have steadily risen and have now reached $12 \%$ in the so called "micromorph" (microcrystalline/amorphous) tandem cell configuration.
\end{abstract}

\section{INTRODUCTION}

Hydrogenated microcrystalline silicon ( $\mu \mathrm{c}-\mathrm{Si}: \mathrm{H}$ ) can be produced at relatively low temperatures (typically 200$300^{\circ} \mathrm{C}$ ) by glow discharge and other forms of plasmaassisted deposition, as well as by hot wire deposition, in a very similar manner to amorphous silicon (a-Si:H).

Compared with polycrystalline silicon as produced e.g. by thermal CVD and by many other high-temperature deposition and crystal growth methods, microcrystalline silicon shows certain characteristic features:

i the grain sizes are, in general, smaller for $\mu \mathrm{c}-\mathrm{Si}: \mathrm{H}$;

ii the grain boundaries are hydrogenated;

iii there can be a significant amount of amorphous tissue in the layer.

Furthermore, one should also note that, as is the case for polycrystalline silicon, the material can be highly anisotropic, and furthermore can at times display microstructure including channels and microvoids and very often considerable surface roughness. The exact type of $\mu \mathrm{c}$-Si:H obtained, is thus, indeed, extremely variable and strongly depends on the exact combination of deposition parameters used. Whereas the method of producing solar cells with the "classical» type of polycrystalline silicon has been inspired by monocrystalline silicon solar cell technology and is based on the use of $p-n$ diodes as devices, the work by our own group and a few other groups $[1,2,3]$ has followed the example of amorphous silicon and is based on the use of $\mathrm{p}-\mathrm{j}-\mathrm{n}$ diodes.

In the latter case, a very effective passivation of midgap defects which are acting as recombination centres in the i-layer (e.g. dangling bonds on the grain boundaries) is essential; furthermore, the presence of a strong and uniform average electric field within the i-layer is important. Therefore, the i-layer thickness should be as low as possible (typically a few microns) and optical absoption enhancement, both due to external and internal factors of light trapping, is absolutely essential.

Whereas the external factors (e.g. use of back reflectors and textured $\mathrm{TCO}$ ) are well known from the aSi:H case, the internal factors are linked to the crystal structure of the $\mu \mathrm{c}$-Si:H layer itself, which, in its turn, influences the surface roughness of the i-layer; they lead to an increase of the "apparent" or "effective" absorption coefficient as measured on individual layers. Because $\mu \mathrm{c}-\mathrm{Si}: H$ is, similar to classical crystalline silicon, basically a material with an indirect bandgap, this increase in the apparent absorption becomes, indeed, a key question. Finally, in order to preserve the electric field within the $\mathrm{i}$-layer it is necessary to obtain $\mu \mathrm{c}$-Si: $\mathrm{H}$ layers with a "true" midgap character and the oxygen, usually present in such layers has to be compensated (e.g. slight boron doping) or suppressed by the use of a gas purifier and other impurity reduction techniques for the deposition reactor [4].

\section{EXPERIMENTAL}

All films and cells, amorphous as well as microcrystalline ones, were deposited in a capacitively coupled parallel plate single-chamber reactor at plasma excitation frequencies in the VHF-range $(70-140 \mathrm{MHz})$. Detailled descriptions of the fabrication of amorphous silicon cells from the application in the micromorph tandem cells are given eleswhere [5,6], whereas details for the whole $\mu \mathrm{c}-\mathrm{Si} \mathrm{H} \mathrm{p}-\mathrm{i}-\mathrm{n}$ cell fabrication using the purifier method can be found in earlier studies [7]. Complementary information on undoped $\mu \mathrm{c}$-Si:H growth can be found in another recent paper [5]. Films were grown on sodium-free glass substrates. The micromorph tandems and entirely $\mu \mathrm{c}-\mathrm{Si}: \mathrm{H} p-\mathrm{i}-\mathrm{n}$ single cells were deposited on $\mathrm{SnO}_{2}$-coated glass substrates (Asahi type U). The TCO/Ag back contact was realised either by ITO or ZnO. Light-soaking experiments on micromorph tandem cells were performed under spectral conditions 
close to AM 1.5 at $50^{\circ} \mathrm{C}$ over $1000 \mathrm{~h}$. The I-V curves were measured using a two-source solar simulator (Wacom WXS-140S-10) and outdoor conditions. The cell temperature during light-soaking and measurement was controlled by a Pt 100 sensor pasted on the backside of the cells. The micomorph tandem cells were simultaneously measured with respect to a calibrated reference detector (error $\pm 5 \%$ ).

In order to study the $\mathrm{V}_{\mathrm{OC}}$-dependence of $\mu \mathrm{c}$-Si:H cells, in function of i-layer thickness, a stepwise opening of a shutter during deposition in front of the substrate was performed. To study the chemical stability of $\mu \mathrm{c}-\mathrm{Si}: \mathrm{H}$ with respect to long-term exposure, in ambient air, both films and cells were investigated either by coplanar dark conductivity $\left(\sigma_{\text {dark }}\right)$ or illuminated I-V characterisitics. The $\sigma_{\text {dark }}$-values were taken at $25^{\circ} \mathrm{C}$ in a nitrogen atmosphere after an annealing step at $180^{\circ} \mathrm{C}$.

\section{RESULTS AND DISCUSSION}

\section{Microcrystalline ( $\mu \mathrm{c}-\mathrm{Si}: \mathrm{H})$ layers produced by VHF- Glow Discharge}

Using the VHF-GD method, our group has been able to produce layers with the required properties as described above. Fig. 1 shows the optical absorption spectraof such layers as measured by PDS and CPM. The low value of defect absorption at around $0.8 \mathrm{eV}$ is a clear indication of satisfactory dangling bond $/$ recombination centre passivation.

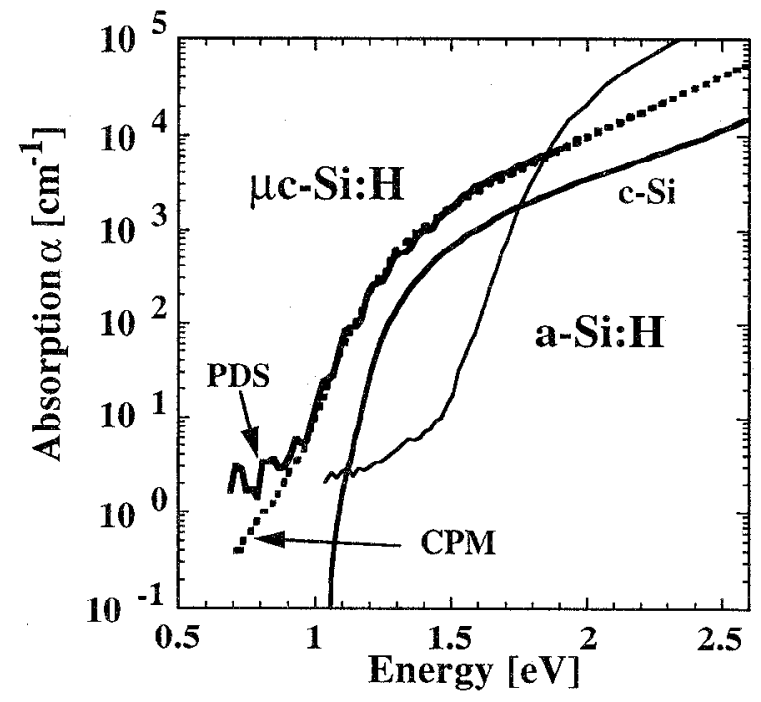

Fig. 1: Comparison of the apparent absorption of c-Si, aSi:H and $\mu c-S i: H$.

On the other hand, above $1.4 \mathrm{cV}$ one needs to have a high value of the absorption coefficient. In this range, absorption by defects is not an important contribution. The measured effective absorption coefficient is increased in the whole range above the values obtained for monocrystalline silicon, but up to $1.8 \mathrm{eV}$ this appears, according to recent studies [8] to be due essentially to optical scattering effects.

As shown by Torres et al. in another paper at this conference, such an enhancement of the optical absorption coefficient is typically linked -at least in the few cases sofar observed by our own group- with a predominace of the (220) peak as observed by X-Ray diffraction measurements. At the same time, the observed samples show pronounced surface roughness which may be the direct cause for the increase of the "effective" optical absorption coefficient.

A further critical test of $\mu \mathrm{c}-\mathrm{Si}: \mathrm{H}$ layer "quality", in addition to PDS/CPM measurements, are constituted by dark / photo conductivity measurements. Typical $\mu \mathrm{c}-\mathrm{Si}: \mathrm{H}$ layers produced by glow-dicharge (and by many other deposition techniques) have a pronounced n-type behaviour, however, with low-level boron doping a "midgap" character can be obtained, identified here by a low value of $\sigma_{\text {dark }}=5 \times 10^{-8}(\Omega \mathrm{cm})^{-1}$.

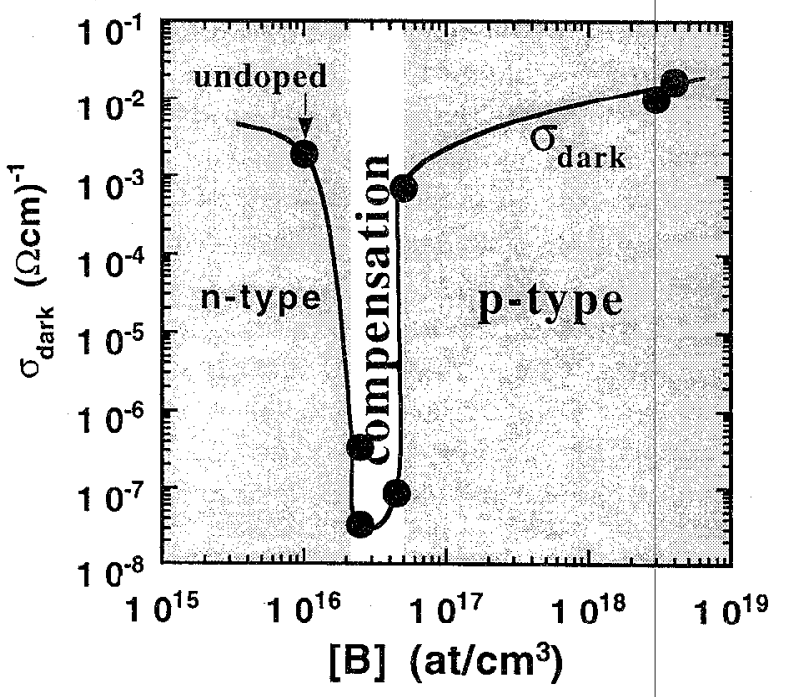

Fig. 2: $\sigma_{\text {dark }}$, vs. boron concentration measured by SIMS Data taken from [9].

Such low values of $\sigma_{d a r k}$ can, also, be obtained by the use of a gas-purifier [7] and this is a clear indication that oxygen incorporation into the layers and not "structural" doping is the reason for the n-type behavior often observed. The relatively high value of the photoconductive gain obtained by midgap layers is an indication for the quality of the material; this ratio can also be used as screening parameter for technological work. 


\subsection{Transport properties}

The measurement of the ambipolar diffusion length by SSPG in the direction parallel to the substrate yields values that are somewhat higher than in device quality a-Si:H layers, typically $L_{a m b}=2500 \AA ̊$ [9]. However, this is not the direction in which collection takes place within the $\mathrm{p}-\mathrm{i}-\mathrm{n}$ solar cell. Note that an indication of the inherent anisotropy is given by the columnar growth of the $\mu \mathrm{c}$-Si:H, notably by the preferential growth in $<220\rangle$ direction Furthermore, it is somewhat speculative to extend the SSPG measurement to the case of $\mu \mathrm{c}-\mathrm{Si}: \mathrm{H}$ without first establishing a new transport model. Time of flight measurements were carried out $[10,11]$ on our device-quality material yielding:

\begin{tabular}{ll}
$\begin{array}{l}\text { drift mobility for electrons } \\
\text { for holes }\end{array}$ & $2.6 \quad \mathrm{~cm}^{2} \mathrm{~N} / \mathrm{s}$ \\
$\mu \tau$-product (electrons) & $1.6 \mathrm{~cm}^{2} \mathrm{Ns}$ \\
\multicolumn{1}{c}{ (holes) } & $1.1 \times 10^{-7} \mathrm{~cm}^{2} \mathrm{~N}$ \\
& $8.0 \times 10^{-8} \mathrm{~cm}^{2} \mathrm{~N}$
\end{tabular}

Time of flight assesses the transport properties in the direction orthogonal to the substrate, i.e. in the direction of actual collection for $p-i-n$ solar cells. The assessment of the $\mu \tau$-product ran, however, into some difficulty and can only be considered a first attempt. Drift mobility measurements include, on the other hand, effect of trapping and this phenomenon is not directly important for solar cell collection in the steady state. From the relatively high value of the hole drift mobility obtained (when compared with a-Si:H) one can at least conclude that "device-grade" $\mu \mathrm{c}$-Si:H layers investigated do not have significant trapping of holes, i.e. a substantial valence bandtail like in a-Si:H is not present.

\section{Entirely $\mu c-$ Si:H single-junction p-i-n cells}

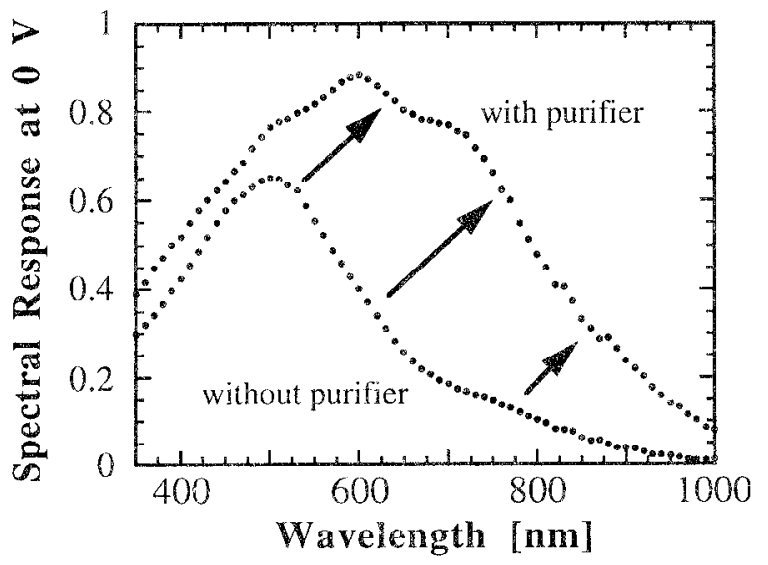

Fig. 3 Comparison of the spectral responses of $2.8 \mu \mathrm{m}$ thick solar cells with and without purifier. The cell yielding upper curve (with purifier) has a midgap i-layer; from [7].
Fig.3 shows the detrimental effect of the n-type character of $\mu \mathrm{c}-\mathrm{Si}: \mathrm{H}$ films on the spectral response (SR) curve for a cell deposited without purifier compared to a cell deposited with purifier.

\section{$2.2 V_{\text {OC }}$ of $\mu \mathrm{c}-\mathrm{Si} \mathrm{H}$ cells: bulk or interface-limited?}

The most important lask for further progress in microcrystaline silicon cells is an enhancement of the present low value of the open circuit voltage. Hence, further research must be addressed to the following questions: can we obtain higher $V_{O C}$-values with $\mu \mathrm{C}$-Si:H materiai at all? Is the mechanism limiting $V_{O C}$ due to bulk or interface properties?

If the presently low $V_{O C}$-values of $450 \mathrm{mV}$ of our cells, has to be attributed to bulk recombination, a substantial variation of the i-layer thickness in the cell should lead to a variation of the $V_{o c}$. Therefore, two cells with $\mathrm{i}$-layer thicknesses of ratio $1: 4$ were deposited in one single run with the help of a shutter in the reactor.

It was found that both colls exactly have the same $\mathrm{V}_{\mathrm{OC}^{-}}$ value. Based on this result, we conclude that bulk recombination plays a minor role to the present low $V_{O C}$ of $\mu \mathrm{c}$-Si:H cells. Thus we are led to hold that the $V_{O C}$ problem has to be faced at the interfaces.

In order to achieve higher $V_{O C}$-values, special treatments of the $p / i$ interface have been carried out. The results of these experiments are summarised in Tab. 1.

\begin{tabular}{|l|c|c|c|c|}
\hline$\eta[\%]$ & 7.7 & 7.5 & 7.7 & 4.4 \\
\hline$J_{S c}\left[\mathrm{~mA} / \mathrm{cm}^{2}\right]$ & 25.3 & 24.0 & 23.5 & 18.2 \\
\hline$F F[\%]$ & 67.9 & 68.1 & 68.4 & 48.0 \\
\hline$V_{O c}[\mathrm{mV}]$ & 448 & 460 & 478 & $\mathbf{4 9 9}$ \\
\hline
\end{tabular}

Tab. 1: Results on $\mu c-$ Si:H p-i-n solar cells with different $\mathrm{p} / \mathrm{i}$ interface treatments.

Higher $V_{\text {oc }}$-values can indeed be obtained, but over $480 \mathrm{mV}$ sofar only combined with a drastic decrease in the fill factor. The reason for this effect is not known. At present we speculate that a further optimisation of the $\mathrm{p} / \mathrm{i}$ interface should hopefully lead us to higher $V_{O C}$-values in combination with reasonable fill factors.

\subsection{Collection mechanism in $\mu \mathrm{c}-\mathrm{Si}: \mathrm{H} \mathrm{p}-\mathrm{i}-\mathrm{n}$ celis}

The following observations have been made w.r.t. the $p-i-n$ solar cells fabricated by our group [10]:

- The average electric field E remains surprisingly uniform even within $2.84 \mathrm{~m}$ thick i-layers of a $p$-i.n diode; from Fig. 3 we also conclude that $E$ plays an important role. 
- Evaluation of dark and illuminated I(V) curves and of integrated spectral response measurements indicate a behaviour that is quite different from that of aSi:H p-i-n diodes and approaches (though not fully) that of monocrystalline $p-n$ diodes; this is an indication that diffusion also plays an important role.

- Preliminary capacitance measurements done on two diodes with different thicknesses [11] seem to indicate that the electric field drop is concentrated in some distinct and geometrically limited regions of the $\mu \mathrm{c}$ $\mathrm{Si}: \mathrm{H}$ diodes; we speculate that these regions must be at least partly identical with the grain-boundaries.

The tentative conclusion is that the transport mechanism within the p-i-n diode is a "mixture" of drift and diffusion that results from the non-uniform nature of the material.

Whereas drift would be the predominant mechanism of carrier separation and transport over the interfaces and grain-boundaries, diffusion may well be the predominant carrier transport mechanism within the grains. The resulting situation (as conjectured by us) is schematically sketched in Fig. 4

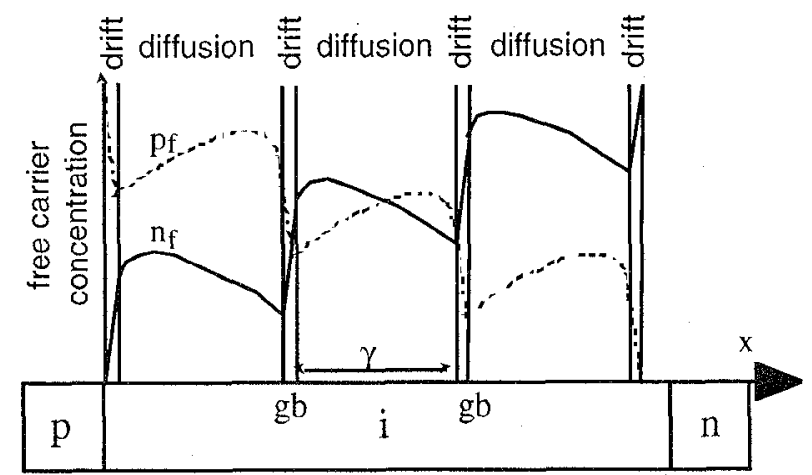

Fig. 4 Assumed schematical free carrier densities $n_{f}, p_{f}$ for combined drift and diffusion scenario in $\mu \mathrm{c}-\mathrm{Si}: \mathrm{H} \mathrm{p}-\mathrm{i}-\mathrm{n}$ solar cells taken from [11]; gb: grain boundary.

\section{STABILITY}

\subsection{Chemical stability.}

As is well known, a native oxidation of the $\mu \mathrm{c}-\mathrm{Si}: \mathrm{H}$ surface starts as soon as the films are exposed to ambient air [12]: an effect that can be observed for crystalline silicon, and to a lesser extent in amorphous silicon as well. Furthermore, variation of atmospheric impurity profiles $(O, N, C)$ near the surface can be attributed to differences in film porousness as demonstrated by secondary ion mass spectroscopy measurements $[4,5,9]$.

Transport properties of individual i-layers in coplanar configuration have recently shown to be strongly influenced by postoxitation [9]. Such a postoxidation via the surface could be a very harmful phenomenon if it was observed on $\mu \mathrm{c}$-Si:H solar cells.

In order to check the phenomenon of post-oxidation in detail, intrinsic films and cells were fabricated with identical deposition conditions for the purified i-layer. In both cases, a gas-purifier was used. Fig. 5 compares the effect of air exposure on the dark conductivity of a film (2.3 $\mu \mathrm{m}$ on glass) and on the AM1.5 efficiency of the corresponding $p-i-n$ cell.

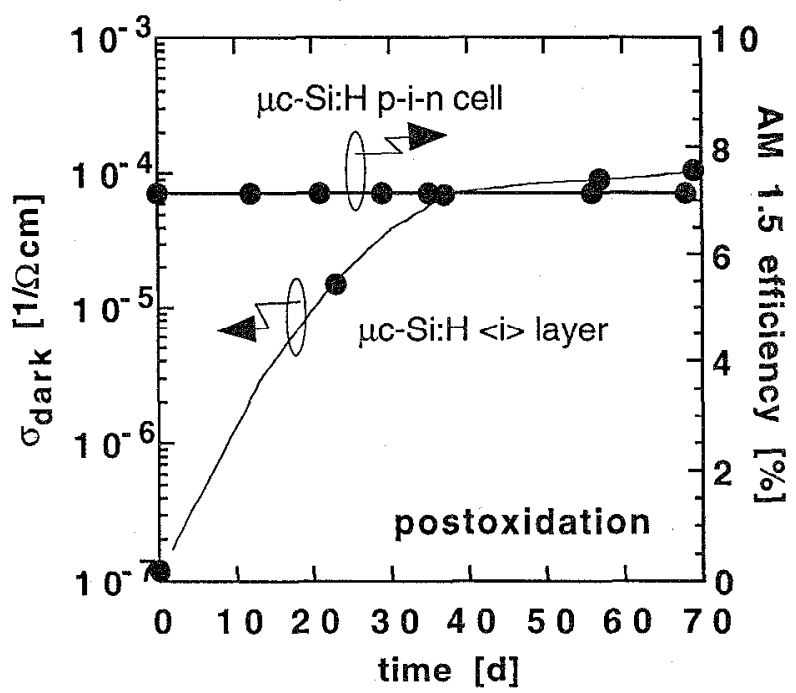

Fig. 5 Chemical stability of cells and individual layers due to postoxidation after deposition. Individual films undergo a strong variation in dark conductivity, whereas the cell efficiency remains constant.

In the individual layer, a dramatic increase of $\sigma_{\text {dark }}$ over three orders of magnitude is observable and can clearly be attributed to postoxidation. In the case shown in Fig. 3 the individual value of the dark activation energy of $E_{a}=524 \mathrm{mV}$ dropped after 70 days to a value of $\mathrm{E}_{\mathrm{a}}=170 \mathrm{mV}$ due to postoxidation. In contrast with this, the solar cell parameters of complete $\mu c-S i: H$ p-i-n cells are not at all affected by air exposure. In the case of micromorph tandem cells, no chemical degradation has been detected even without special encapsulation of the cells, after 18 months of air exposure (ISE-FhG confirmed cells in Tab. 2). Therefore, we are convinced that $\mu \mathrm{c}$-Si:H based cells equipped with state-of-the art encapsulation certainly have the potential for long lifetimes and stability.

\subsection{Light-induced degradation}

As $\mu \mathrm{c}-\mathrm{Si}: \mathrm{H}$ layers probably contain dangling bonds that are partly passivated by hydrogen both at the grain boundaries and certainly also in any amorphous tissue that continues to be present in the material, the question of light-induced degradation (Staebler-Wronski effect) is an important issue. 
Light-induced degradation studies have been carried out on a low-level doping series of individual $\mathrm{i}$ layers (fabricated without gas purifier and having therefore a strong n-type character in the undoped state, due to oxygen).

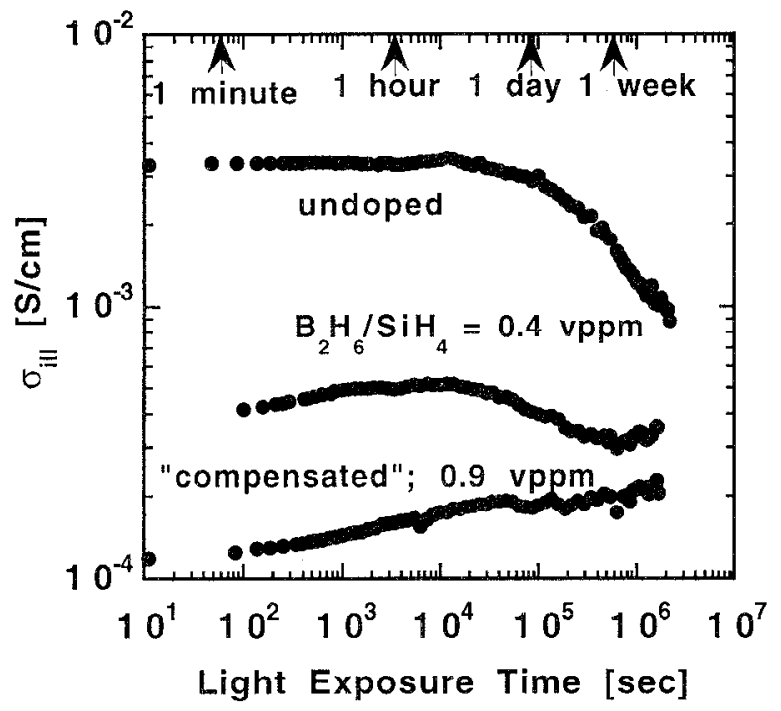

Fig.6: Light-induced degradation of individual intrinsic layers and those that contain small traces of $p$ and $n$ dopants [13]. $\sigma_{i l l}$ is the total conductivity measured under illumination. After $10^{6} \mathrm{~s}$ erratic behaviour was observed, possibly due to postoxidation problems.

Result are shown in Fig. 6: whereas the "undoped" n-type layers are subject to light-induced degradation, midgap (compensated) layers appear to be rather stable. The $0.9 \mathrm{vppm}$ (compensated or slightly $\mathrm{p}$-type) layer shows a strange behaviour, i.e. an increase in $\sigma_{i l l}$ with light exposure.

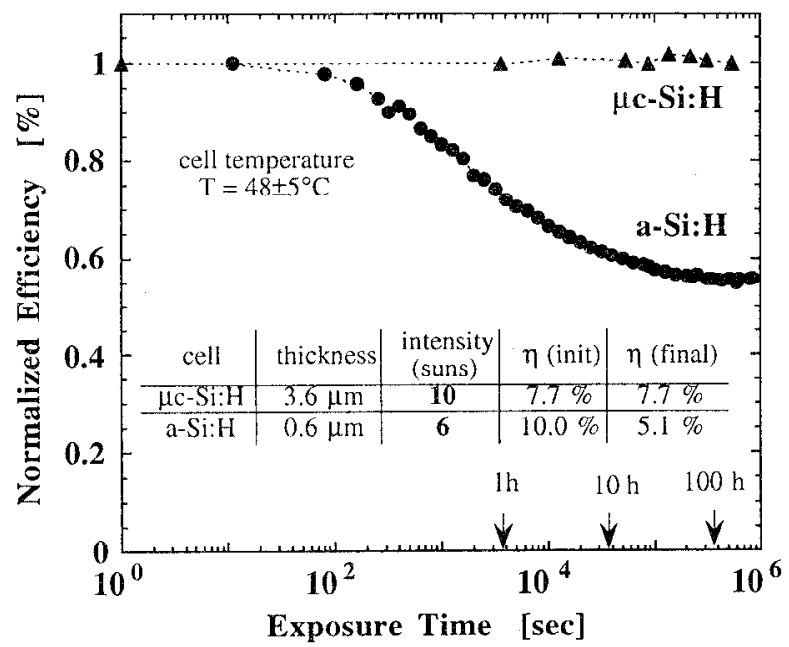

Fig. 7: Comparison of the degradation behaviour of an amorphous and a microcrystalline p-i-n solar cell. [5]
On the other hand, all complete $\mu \mathrm{c}$-Si:H p-i-n solar cells fabricated and tested by our group have shown absolutely no light-induced degradation, as illustrated typically in Fig. 7. It is, furthermore, important to remember that the properties of $\mu \mathrm{c}$-Si:H vary strongly with deposition conditions. Therefore, this problem must be carefully monitored during future work. It would be misleading to say that $\mu \mathrm{C}-\mathrm{Si}: H$ has per se no StaeblerWronski effect.

\section{Reduction of the i-layer deposition time}

Originally, our $p-i-n$ diodes that have i-layer thicknesses of about $3 \mu \mathrm{m}$ were deposited at rates around $1 \AA / s$; thus, their preparation typically took several hours. While this continues to be approximately the deposition rate used for our best diodes, parallel work has been done to find ways of increasing the deposition rate. It has been shown that various strategies, like increase in the plasma excitation frequency, increase of the plasma power and, also, argon dilution can be used to increase the deposition rate $[14,15]$. Test diodes of the metal-n-i-p type (without optimized external light-trapping) have thereby been fabricated and indicate that deposition rates higher than $10 \AA / s$ can be attained without any relative decrease in the diode efficiency. As an example, $P$. Torres et al. present at this conference results on a $\mu \mathrm{c}$ $\mathrm{Si} H$ diode fabricated at more than $10 \AA / \mathrm{s}$ and attaining $5.1 \%$ efficiency [14].

On the other hand, another group has shown, that with very sophisticated light-trapping schemes, $\mu \mathrm{c}-\mathrm{Si}: \mathrm{H}$ diodes can be fabricated, albeit at a much higher deposition temperature, with an excellent AM1.5 efficiency $(9 \%)$ and a decent spectral response in the near infrared and this at a thickness as low as $1.5 \mu \mathrm{m}$ [3] .

If one can now combine such a reduced thickness with our fast high-rate deposition techniques, deposition times of about half an hour may become a realistic possibility. Still, this aspect remains the most critical barrier to the use of $\mu \mathrm{C}-\mathrm{Si}: \mathrm{H}$ in commercial solar cells.

\section{5. "Micromorph" tandem cells}

Different amorphous silicon top cells were combined with $\mu \mathrm{c}-\mathrm{Si}: \mathrm{H}$ silicon bottom cells with open circuit voltages of 440 to $450 \mathrm{mV}$. These micromorph (microcrystalline lamorphous) tandem cells were light-soaked as described. For an older set of stabilized tandem cells, an efficiency of $10.7 \%$ has been confirmed by ISE-FhG (Freiburg, Germany). This older set of tandems was provided with strongly $\mathrm{H}$-diluted amorphous top cells $(0.21 \mu \mathrm{m}$ thickness $)$ in order to increase their stability and the $V_{\text {oc }}$. The spectral response analysis showed, however, that in this case, the short circuit current of the 
amorphous top cell is too low and limits the efficiency of the tandem.

Therefore, in a new set of micromorph tandem cells, undiluted top cells $(0.32 \mu \mathrm{m}$ thickness) with a lower energy gap ( $E_{03}$ of about $1.72 \mathrm{eV}$ ) were used. A further improvement of the recombination junction between top and bottom cells was also incorporated into these tandems. These cells were light-soaked over $1000 \mathrm{~h}$ like the former ones. The comparison of the new generation of tandems with the earlier ones (Tab. 2) shows, indeed, an improvement of the efficiency up to $12 \%$ when based on outdoor conditions.

Clearly, low-gap a-Si:H material contributes to better current matching between top and bottom cell. In fact, the micomorph cell can thus benefit from the high current potential of the $\mu \mathrm{c}-\mathrm{Si}: \mathrm{H}$ bottom cell.

\begin{tabular}{|l|c|c|c|}
\multicolumn{1}{c|}{} & \multicolumn{2}{c|}{$\begin{array}{c}\text { earlier tandem } \\
\text { (H2-diluted a-Si:H top })\end{array}$} & $\begin{array}{c}\text { recent tand. } \\
\text { (undil.top })\end{array}$ \\
\cline { 2 - 4 } \multicolumn{1}{c|}{} & $\begin{array}{c}\text { ISE-FhG } \\
\text { Freiburg }\end{array}$ & $\begin{array}{c}\text { outdoor } \\
\text { at } 25^{\circ} \mathrm{C}\end{array}$ & $\begin{array}{c}\text { outdoor } \\
\text { at 25 }{ }^{\circ} \mathrm{C}\end{array}$ \\
\hline$J_{S C}\left[\mathrm{~mA} / \mathrm{cm}^{2}\right]$ & 11.9 & 12.6 & 13.5 \\
\hline$V_{O C}[\mathrm{~V}]$ & 1.34 & 1.34 & 1.28 \\
\hline$F F$ & 66.7 & 66.9 & 69.2 \\
\hline$\eta[\%]$ & $10.7 \pm 0.7$ & $\mathbf{1 1 . 3} \pm \mathbf{0 . 6}$ & $\mathbf{1 2 . 0 \pm 0 . 6}$ \\
\hline
\end{tabular}

Tab. 2: Results obtained on 2 series of "micromorph" tandem cells: $J_{S C}$ increases and $V_{O C}$ decreases because of the lower $\mathrm{Eg}$ of the top cell; FF increases because of an improved recombination junction.

For Table 2, stabilized micromorph tandem cells (1000 $\mathrm{h}$ light-soaked) were measured at the ISE-FhG Freiburg (Germany) or under outdoor illumination of 93$95 \mathrm{~mW} / \mathrm{cm}^{2}$ (clear, cloudless sky conditions at noon in Neuchâtel on the $9^{\text {th }}$ and $21^{\text {st }}$ of July 1997) The Jscvalues given are normalized to $100 \mathrm{~mW} / \mathrm{cm}^{2}$ for comparison. Difference in $J_{S c}$ between laboratory and outdoor measurements may be attributed to the fact that AM1.5 conditions can only approximately be obtained with an "artificial" sunlight source.

\section{CONCLUSIONS}

- Hydrogenated microcrystalline silicon ( $\mu \mathrm{c}-\mathrm{Si}: \mathrm{H})$ can be an interesting photovoltaically active material.

- It can be advantageously deposited by VHF plasma CVD at low temperatures $\left(T<250^{\circ} \mathrm{C}\right)$
- $p$-i-n solar cells with $\mu c-S i: H$ work (presumably) with a combination of drift and diffusion.

- Mircromorph (microcrystalline / amorphous) silicon tandems have attained some 12\% (AM1.5) stable efficiency

\section{ACKNOWLEDGEMENTS}

This work was supported by Swiss Federal Department of Energy BEW/OFEN, Project Nr. 19431.

\section{REFERENCES}

[1] C. Wang and G. Lucowsky, Proc. 21st IEEE PVSC, 1990, Vol. 2, pp 1614-1618.

[2] M. Faraj, S. Gokhale, S. M. Choudhari, and M. G. Takwale, Appl. Phys. Lett. 60, 1992 p. 3289,

[3] K. Yamamoto et al. 14th EC PVSEC 1997 to be publ.

[4] U. Kroll, J. Meier, H. Keppner, and A. Shah, J. Vac.

Sci. Technol. A 13(6) 1995 p. 2742, .

[5] J. Meier, P. Torres, R. Platz, S. Dubail, U. Kroll, J.A. Anna Selvan, N. Pellaton-Vaucher, Ch. Hof, D. Fischer, H. Keppner, A. Shah, K.-D. Ufert, P. Giannoulès, J. Koehler, Proc. MRS 420, 1996, p.3

[6] J. Meier et al., to be publ, in the Proc. ICAMS-97.

[7] P. Torres, J. Meier, R. Flückiger, U. Kroll, J. A. A. Selvan, H. Keppner, A. Shah, S. D. Littlewood, I. E. Kelly, and P. Giannoulès, Appl. Phys. Lett. 69, 1996, p. 1373.

[8] M. Vanecek et al., to be publ. in the Proc. ICAMS-97

[9] M. Goerlitzer et al., to be publ. in Proc. ICAMS-97

[10] N.Wyrsch et al. to be publ. in the Proc. ICAMS-97

[11] N. Beck PhD Thesis, Neuchâtel 1997

[12] S. Veprek, Z. Iqbal, R.O. Kühne, P. Capezzuto, F-A. Sarott and J. K. Grimzewski, J. Phys. C: Solid State Phys., 16, 1983, pp. 6241-6262

[13] R. Flückiger, PhD Thesis, Hartung-Gorre Verlag Konstanz, ISBN 3-89191-965-4

[14] P. Torres et al., this conference.

[15] H. Keppner, P. Torres, J. Meier, R. Platz, D. Fischer, U. Kroll, S. Dubail, J.A.AnnaSelvan, N.P. Vaucher, Y. Ziegler, R. Tscharner, C. Hof, N. Beck, M. Goetz, P. Pernet, M. Goerlitzer, N. Wyrsch, J. Vuille, J. Cuperus, A. Shah, J. Pohl, Proc MRS 452, 1996, p. 865 